\title{
Improvement of Forest Canopy Density Mapping of Spare Forests Using a Novel RS-GIS Based Classification Method
}

Mohammad Hassan Naseri

Gorgan University of Agricultural Sciences and Natural Resources

Shaban Shataee ( $\sim$ shataee@gau.ac.ir)

Gorgan University of Agricultural Sciences and Natural Resources https://orcid.org/0000-0002-38688475

\section{Research}

Keywords: Canopy cover, Sparse forest, High-resolution images, RS-GIS based, Optimal plot area

Posted Date: January 13th, 2021

DOl: https://doi.org/10.21203/rs.3.rs-143010/v1

License: (c) (i) This work is licensed under a Creative Commons Attribution 4.0 International License.

Read Full License 


\section{Abstract}

Background: Accurate mapping and monitoring canopy cover using remote sensing data as an alternative way for field surveys are very important for forest managers, particularly in the spare and low dense forests. Due to being area-based of canopy cover density and mixing spectral responses of tree crowns and soil in the thin and semi-dense forests, finding the high-performance method of classification is a challenge particularly on high-resolution imagery. In this study, we compared produced maps of canopy cover using direct remote sensing and indirect (RS-GIS-based) methods in two forest sites on the Quickbird and WorldView-2 images using the Artificial Neural Network (ANN) algorithm. Also, the optimal plot area was examined by different plot areas.

Results: In the direct method and based on the obtained results, in the Dashte Barm using Quickbird image, the best classification was for plots of $7500 \mathrm{~m}^{2}$ with an overall accuracy of $56.57 \%$ and kappa coefficient of 0.32 . In the llam site and on the WorldView-2 image, the best result is obtained by the plots of $5,000 \mathrm{~m}^{2}$ area with an overall accuracy of $45.71 \%$ and the kappa coefficient of 0.263 . The results of accuracy assessment of maps of indirect method in the Dashte Barm site for grids with different areas showed that the best classifications obtained from sample plot areas of $10000 \mathrm{~m}^{2}$ with overall accuracy of $82.69 \%$ and Kappa coefficient of 0.744 ; but in the llam sites the best result was obtained using sample area of $1000 \mathrm{~m}^{2}$ with overall accuracy of $74.27 \%$ and the Kappa coefficient of 0.690 .

Conclusions: The results exposed that use of the RS-GIS based method could considerably improve the results compare to direct classification. Also, the results showed concerning the conditions of canopy cover density of forest stands, plots with different areas can be used to map of forest canopy cover density; however, for direct classification the use of plots with areas of $5000 \mathrm{~m}^{2}$ and more are suitable in sparse forests. For RS-GIS based method, the plot areas of $1000 \mathrm{~m}^{2}$ are optimal due to time and cost saving.

\section{Background}

Iran is one of the countries with low forest cover, which clearly shows the importance of protecting existing forests. One of the most important vegetation areas in Iran is the Zagros forests, which have long been inhabited by residents and nomads and have been exposed to several damages, which have led to the destruction of parts of these forests. Therefore, the management and monitoring of these forests require a lot of management factors (Afshar 2012).

The forest canopy cover density has a special role in the forest ecosystem and its protection. From a point of ecological view, one of the most important components of the forest ecosystem is the canopy cover (TaheriSarteshnizi 2013), which plays an important role in preserving the forest ecosystem's biodiversity, affecting microclimate and soil characteristics. Forest cover plays a major role in hydrological cycles, temperature systems as well as biochemical cycles. The stability and destruction of vegetation are often a function of the cover and thickness of the canopy so that it can often be 
considered as a quantitative and qualitative component of the production of plant communities (Behbahani et al. 2009).

Canopy cover density classes maps are the area-based parameter where the percentage of canopy cover of trees were computed based on the crown area of trees in a certain area such as plots or other suitable defined polygons by forest managers. However, it should be considered that canopy cover as vertical projections of tree crowns is the sum of the individual crown areas minus their overlapping crown areas (Williams et al., 2003). This area-based parameter can provide useful information for forest management so that preparing the canopy cover density maps is one of the basic information in almost forest management plans particularly in the arid or semi-arid regions with sparse or semi sparse forests. The canopy cover density is generally computed on an area such as topographical-vegetation homogeneous polygons or predefined knowledge-based grids through the field surveying or interpretation of aerial photos, which are generally time and cost consuming. One of the alternative sources and ways is using satellite imagery and remote sensing techniques on especially high-resolution imagery (Parma and Shataee 2010; Naghavi et al., 2014). On other hand, Banerjee et al. (2014) emphasize that understanding the capability and limitations of various types of imagery and classification methods is essential to interpreting canopy cover and forest canopy density mapping. In this line, some researchers (Parma and Shataee, 2010; Abdollahi et al. 2010; Nourian et al., 2016; Abdollahnejad et al., 2017; Asrat et al., 2018) concluded that different types of satellite sensors can result in different outputs due to their various spectral and spatial resolutions. One of the traditional methods is the classification of remote sensing images with appropriate spectral and spatial resolution through pixel-based algorithms. In this regard, some researchers (Parma and Shataee, 2010; Abdollahi et al., 2010a; Shahvali et al., 2012; Eskandari et al., 2020; Mahdavi and Aziz, 2020) using the medium to high-resolution images tried to generate canopy cover density maps in this forest zone, but in the most of studies, researchers could not obtain the favorite results. This unsatisfied result from the use of medium resolution imagery refers to some reasons such as existing the mixed pixels due to be mixing spectral responses of tree cover with ground spectral i.e. bare soil or herbal vegetation at a high dimensions pixel especially in the very sparse forests; as well as to be mixed of spectral responses of two or more different density classes in a pixel especial in the boundary of density classes. It seems that one of the solutions to overcome these mixed pixels is using high-resolution images and classifying images by pixel or object-based classifiers or using novel methods for improvement of the results.

Although the use of the pixel-based classification is one of the most used methods for classifying highresolution images (Kim et al. 2011), however, it causes many problems due to being area-based of classification objects like forest canopy cover density classes. Due to the presence of shadows and gaps in the sparse forests, and also spectral diversity, structural composition, and heterogeneity in a class, it may lead to errors in differentiating different classes (Bauer and Steinnocher 2001). Since, various methods have been used to solve such problems, such as image pre-processing, such as low-pass filter and texture analysis, contextual classification, such as Markov random field, and post-classification processing, such as mode filtering, morphological filtering, and rule-based processing (Kim et al., 2011). Erfanifard et al. (2014) suggested a robust approach to generate canopy cover maps using UltraCam-D 
derived orthoimagery, which is classified by support vector machines algorithm in Zagros forest zone, West Iran.

In addition, the use of object-based methods has recently been used to solve the mentioned problems. This classification uses membership functions to assign each object to the appropriate class (Quynh Trang et al. 2016). In this regard, Rahimizadeh et al. (2020) used the object-based method to study the canopy cover of trees using the Spot-7 satellite image in the high dense forests of Hyrcanian forests (northern Iran) and could improve the results compare to pixel-based classification methods. Also, Wang et al. (2004) used the object-based classification method on the high-resolution Ikonos imagery to study the mangrove forest cover in the Caribbean coast of Panama on the high dense canopy-covered area. They stated that the combination of the pixel-based and object-based methods could improve the results.

In general, from these literature reviews on both pixel and object-based methods using medium or highresolution images, it can be found that canopy cover density mapping in the high dense forests has lesser problems compared to the sparse forest like Zagros forests of Iran. However, in the sparse forest regions, we need to find new suitable methods to overcome these problems.

In line with, Geographical Information Systems (GIS) and its powerful tools assembled on software such as ArcGIS is a computer-based system that capture, prepare, manage, manipulate, analyze, and present geo-referenced data (Ogwankwa 2020). It is assumed that the use of these capabilities can improve the forest canopy cover density mapping in the low dense or sparse forest zones. The GIS and vegetation classification systems in conjunction with computer-based automated field mapping techniques have been prepared the appropriate tools in the process of creating or up-to-dating the vegetation maps (Ismail 2010). In a research which was done on the Zagros forest (Erfanifard et al., 2014), the capability of GIS tools is used to map the forest canopy cover density classes as a robust or novelty method to improve the classification results.

On the other hand, choosing an appropriate plot area for forest canopy cover density mapping is very critical due to the spatial variation of forest canopy cover classes in the Zagros forest zone. So, some researchers have done some studies (Adeli et al., 2008; Mahdavi and Aziz, 2020) in semi-arid forest zones to find the best plot area for field canopy cover surveys. For instance, Adeli et al. (2008) stated and suggested the different sample areas for different forest canopy cover density classes. Since the plot area can affect forest canopy cover estimations both in field surveys and remote sensing surveys; finding an optimal plot area is very important particularly when using high-resolution images.

Given the above and the importance of the canopy in forest resource management, it is important to provide a method that can provide quality information in a short time. Therefore, in this study, Quickbird and WorldView-2 images were classified using the direct (plot-based classification) and RS/GIS-based (indirect) method, which is an experimental and new method, and the canopy cover map of trees in two the area was extracted from the forests of Zagros. The main purpose of this study is to provide a new way to provide higher-quality forest canopy cover density maps. Besides, finding the optimal plot area for 
forest canopy cover mapping in sparse forests like Zagros forest using high-resolution images is the second propose in this research.

\section{Methods}

\section{Study areas}

The study areas were located in two sites in two different spare and semi-dense forest zone. These sites were selected based on the availability of two high-resolution satellite data sets i.e. Quickbird (Dashte Barm) and WorldView-2 (Ilam) that were purchased and used in other studies (Fig. 1).

\section{Dashte Barm site}

Dashte Barm site is located in the region of Kazeron County, Fars province, south of Iran with an area of 2407.8 hectares. The minimum and maximum altitudes of the area are ranging from 1200 and 2900 meters above sea level. In this area, Iranian oak trees (Quercus Brantii) are the dominant species together with some trees and shrubs as rare and low frequency (Naseri et al., 2019).

\section{Ilam site}

This part of the Zagros forests with an area of about 1722.97 hectares, located in the east north of llam city, llam Province, west of Iran. The minimum and maximum altitude of this site are about 1440 and 2324 meters above sea level, respectively. The oak stands (Quercus Brantii) is often pure and in some places are comprising species such as Cercis siliquastrum, Crataegus azarolus, Daphne mucronata, and Prunus scoparia (Karami et al. 2017). In both areas, there are mostly coppice trees.

\section{Ground truth data}

The forest canopy cover density maps were prepared on sample plots where distributed and selected randomly using a combination of field survey, visual and digital interpretation of fused satellite images trough fusion of bands (multispectral and panchromatic bands) of Quickbird and WorldView-2 images, as well as the use of Google earth images in both sites. Totally, 52 quadrangular concentric plots for the Dashte Barm and 60 quadrangular concentric plots for the llam were designed and implemented randomly in the field (Fig. 3) with areas of 1000, 1500, 2500, 5000, 7500 and $10000 \mathrm{~m}^{2}$. The percentages of canopy cover of plots were computed based on measuring the crown area of whole trees in each quadrangle. The percent of canopy cover area was classified into five classes including very thin (1$10 \%)$, thin (10-25\%), semi-dense (25-50\%), massive (50-75\%) and very massive (75-100\%) based on the Iranian FRWMO guideline. It should be considered that the class of very massive does not exist on both sites. Then, $70 \%$ of the plots from each class were considered for training samples, and $30 \%$ of the rest samples were selected for validation of the results. Figure 2 shows the spatial distribution of plot centers.

\section{Remote sensing data}


In this study, the high-resolution images of Quickbird (Dasht Barm site) and WorldView-2 (Ilam site) were used for classification (Fig. 3). The Quickbird satellite images are composing four color bands (blue, green, red, and near-infrared), and a panchromatic band; and WorldView-2 images comprising eight color bands and a panchromatic band (see Table 1).

Table 1

Specifications of Quickbird and WorldView-2 images

\begin{tabular}{|c|c|c|}
\hline Satellite image & Parameter & Bands \\
\hline \multirow[t]{7}{*}{ Quickbird } & \multirow[t]{2}{*}{ Ground resolution } & Pan: $61 \mathrm{~cm}$ \\
\hline & & MS: $2.44 \mathrm{~m}$ \\
\hline & \multirow[t]{5}{*}{ Spectral range } & Pan: $450-900 \mathrm{~nm}$ \\
\hline & & Blue: $450-520 \mathrm{~nm}$ \\
\hline & & Green: $520-600 \mathrm{~nm}$ \\
\hline & & Red: $630-692 \mathrm{~nm}$ \\
\hline & & Near IR: $760-900 \mathrm{~nm}$ \\
\hline \multirow[t]{11}{*}{ WorldView-2 } & \multirow[t]{2}{*}{ Ground resolution } & Pan: $46 \mathrm{~cm}$ \\
\hline & & MS: $1.84 \mathrm{~m}$ \\
\hline & \multirow[t]{9}{*}{ Spectral range } & Pan: $450-800 \mathrm{~nm}$ \\
\hline & & Coastal: $400-450 \mathrm{~nm}$ \\
\hline & & Blue: $450-510 \mathrm{~nm}$ \\
\hline & & Green: $510-580 \mathrm{~nm}$ \\
\hline & & Yellow: $585-626 \mathrm{~nm}$ \\
\hline & & Red: $630-690 \mathrm{~nm}$ \\
\hline & & Red edge: $705-745 \mathrm{~nm}$ \\
\hline & & Near IR-1: 770-895 nm \\
\hline & & Near IR-2: 860-1040 nm \\
\hline
\end{tabular}

\section{Image processing}

Data preprocessing is one of the most important steps in image processing. The type and manner of performing this operation depend on factors such as the type of data used and the purpose of the research (Saraskanrood et al. 2019). Both used images were orthorectified using enough ground control points and DEM of the study area. Then, to accurate extract tree crowns, multispectral and panchromatic bands were pan sharpened using the Brovey method, so that the fine resolution multispectral images with 
61 and 46 centimeters of Quickbird and WorldVeiw-2 fused bands were prepared for classification and fine extraction of tree crowns. In addition, some important vegetation indices of NDVI, GNDVI, and SAVI were also created (Table 2) and used together with other bands in the classification.

\section{Table 2- Vegetation indices}

\begin{tabular}{ccc}
\hline Index & Formula & Source \\
\hline SAVI & $\frac{\mathrm{NIR}-\mathrm{R}}{\mathrm{NIR}+\mathrm{R}+\mathrm{L}}(\mathrm{L}+1)$ & Birth and McVey. (1968) \\
NDVI & $\frac{\mathrm{NIR}-\mathrm{R}}{\mathrm{NIR}+\mathrm{R}}$ & Rouse Jr et al. (1974) \\
& $\frac{\mathrm{NIR}-\mathrm{G}}{\mathrm{NIR}+\mathrm{G}}$ & Gitelson, n.d. (1997) \\
\hline
\end{tabular}

\section{Classification}

The first step for classification images is the definition and selection of class thresholds according to the characteristics of the study area and satellite images (Boyaci et al. 2017) as well as based on guidelines of responsible organizations. Therefore, five classes based on the guidelines of FRWO were considered to prepare a canopy cover map in the study areas. For the investigation on the optimal plot area, classifications were done with Quadrangular areas of 1000, 1500, 2500, 5000, 75000 and $10000 \mathrm{~m}^{2}$. The classifications were performed using an Artificial Neural Network (ANN) algorithm. This algorithm is an information processing system composed of the structure and function of the physiological human brain neural network and some theoretical abstraction, simplification, and simulation of several basic characteristics (Xu et al. 2020). The images were classified by two methods, including direct and indirect (RS-GIS based) methods.

\section{Direct method}

In this method, the classification of images (pan-sharpened bands together with vegetation indices) was done using Artificial Neural Network (ANN) algorithm and the function Sigmoid or Logistic Activation Function (Fig. 4) by 70 percent of samples taken in each canopy cover class by field surveys and Google earth images. All sigmoid functions have the property that they map the entire number line into a small range such as between 0 and 1 (Bonnell 2011). The classifications were repeated for different sample areas. The accuracy assessment of the classified maps was evaluated using test samples (30\%).

\section{Indirect (RS-GIS based) method}


In this method, firstly, the tree and non-tree objects (i.e. bare soil and roads) were separated through the classification of the pan-sharpened images (Brovy method) together with vegetation indices using the ANN algorithm and Sigmoid or Logistic Activation Function. Table 3 shows the number of training pixels for each class. The accuracy of classification results was assessed by test samples.

Table 3

Number of samples for each class in the indirect classification

\begin{tabular}{|lll|}
\hline Image & Classes & Number of samples (pixels) \\
\hline Quickbird & tree & 142 \\
\cline { 2 - 3 } & bare soil & 142 \\
\cline { 2 - 3 } WorldView-2 & tree & 70 \\
\cline { 2 - 3 } & bare soil & 221 \\
& road & 85 \\
\hline
\end{tabular}

Then, using ArcGIS software tools, the images were reclassified into two classes of trees, and non-trees by merging bare land and roads; then the reclassified image rasters were converted to polygon vector shapefiles. The study areas were gridded into 1,$000 ; 1,500 ; 2,500 ; 5,000 ; 7,500$ and $10,000 \mathrm{~m}^{2}$ polygonal grids, and the percentage of canopy cover was calculated in each polygonal grid based on the sum of tree crown area in each grid by intersection function. In the next step, the canopy cover density maps were prepared based on canopy cover density classes. The polygonal canopy cover density classes were again converted to raster format for accuracy assessment. The accuracy assessment of obtained maps was done using test samples. It should be noted that the test samples which are used to evaluate the classification results, were the same ones that were used in the direct classification method to avoid uncertainties.

\section{Results}

\section{Direct-method}

In the direct method, the forest canopy cover density map was obtained using the classification of satellite images with areas of $1000,1500,2500,5000,7500$, and $10000 \mathrm{~m}^{2}$ and ANN algorithm. According to the obtained results (Table 4), in the Dashte Barm site using Quickbird image, the best classification is related to $7500 \mathrm{~m}^{2}$ plots with an overall accuracy of $56.57 \%$ and kappa coefficient of 0.32 (Fig. 5-a) and the lowest result came from $1000 \mathrm{~m}^{2}$ samples (overall accuracy of $48.15 \%$ with a kappa coefficient of 0.247 ). Since the Dashte Barm site is a very spare and low-cover forest area, only three forest canopy cover density classes were classified using the ANN algorithm. Also, in the llam site 
and on the WorldView-2 image, the best result is obtained by the samples of 5,000 $\mathrm{m}^{2}$ area with an overall accuracy of $45.71 \%$ and the kappa coefficient of 0.263 (Fig. 5-b). The lowest result belongs to the $1000 \mathrm{~m}^{2}$ samples (overall accuracy of $38.13 \%$ with a kappa coefficient of 0.160 ). In this site (llam), the amount of canopy is richer and there are classes with a high percentage of canopy cover, but the very dense class has not been seen in the study area.

Table 4

Results of accuracy assessment of the canopy cover maps in the direct method.

\begin{tabular}{|llllllll|}
\hline \multirow{2}{*}{ Image } & Accuracy & \multicolumn{7}{c|}{ Sample area $\left(\mathrm{m}^{2}\right)$} & & & \\
\cline { 3 - 8 } & & $\mathbf{1 0 0 0}$ & $\mathbf{1 5 0 0}$ & $\mathbf{2 5 0 0}$ & $\mathbf{5 0 0 0}$ & $\mathbf{7 5 0 0}$ & $\mathbf{1 0 0 0 0}$ \\
\hline \multirow{2}{*}{ Quickbird } & Overall accuracy (\%) & 48.15 & 51.83 & 51.25 & 57.39 & 56.57 & 53.47 \\
\cline { 2 - 8 } & Kappa coefficient & 0.247 & 0.195 & 0.184 & 0.289 & 0.320 & 0.293 \\
\hline \multirow{2}{*}{ WorldView-2 } & Overall accuracy (\%) & 38.13 & 38.20 & 42.42 & 45.71 & 43.76 & 46.27 \\
\cline { 2 - 8 } & Kappa coefficient & 0.160 & 0.162 & 0.176 & 0.263 & 0.212 & 0.253 \\
\hline
\end{tabular}

\section{Indirect method (RS-GIS based method)}

In this method, first, the pan-sharpened images were classified into different classes (trees, roads, and bare land) using point training samples and then roads and bare land classes were merged. The results of the accuracy assessment of the classified images can be seen in Table 5.

Table 5

Results of accuracy assessment of classified images (tree and non-tree).

\begin{tabular}{|lll|}
\hline Image & Overall accuracy (\%) & Kappa coefficient \\
\hline Quickbird (Dashte Barm site) & 95.454 & 0.930 \\
\hline WorldView-2 (Ilam site) & 97.142 & 0.960 \\
\hline
\end{tabular}

In the second step, each image was divided into 1000, 1500, 2500, 5000, 75000, and $10000 \mathrm{~m}^{2}$ grids, and the percentage of tree canopy cover for each grid was calculated based on areas of tree polygons and area of grids. Figure 6 shows the tree crown area polygons obtained from two-class classification of Quickbird images and the grids with different areas.

The results of accuracy assessment of canopy cover maps in the Dashte Barm site for grids with different areas showed that the best classifications obtained from sample plot areas of $10000 \mathrm{~m}^{2}$ (overall accuracy of $82.69 \%$ and Kappa coefficient of 0.744) (Fig. 7-a); but in the llam sites the best result was using sample area of $1000 \mathrm{~m}^{2}$ (overall accuracy of $74.27 \%$ and the Kappa coefficient of 0.690 ) (Fig. 7-b) (Table 6). 
Table 6

Results of evaluating the accuracy of canopy cover maps of trees in the indirect method (RSGIS based method)

\begin{tabular}{|llllllll|}
\hline Image & Producer Accuracy & \multicolumn{2}{c|}{ Plot area $\left(\mathrm{m}^{2}\right)$} & & & & \\
\cline { 3 - 8 } & & $\mathbf{1 0 0 0}$ & $\mathbf{1 5 0 0}$ & $\mathbf{2 5 0 0}$ & $\mathbf{5 0 0 0}$ & $\mathbf{7 5 0 0}$ & 10000 \\
\hline \multirow{2}{*}{ Quickbird } & Overall accuracy (\%) & 77.39 & 75.41 & 70.52 & 74.56 & 77.59 & 82.69 \\
\cline { 2 - 8 } & Kappa coefficient & 0.683 & 0.632 & 0.562 & 0.617 & 0.673 & 0.744 \\
\hline \multirow{2}{*}{ WorldView-2 } & Overall accuracy (\%) & 74.27 & 61.12 & 56.05 & 51.78 & 56.41 & 61.02 \\
\cline { 2 - 8 } & Kappa coefficient & 0.690 & 0.533 & 0.456 & 0.424 & 0.470 & 0.512 \\
\hline
\end{tabular}

\section{Optimal plot area}

The optimal plot area for measuring and classifying the canopy cover of trees was investigated for two methods in this study. In the direct classification method, the area of the plots did not have a significant effect on the classification results. However, in the Dashte Barm site (Quickbird image), using the plot area of 5,000 $\mathrm{m}^{2}$, and the llam site (WorldView-2 image), the plot area of $10,000 \mathrm{~m}^{2}$ could slightly improve the classification results. In the RS-GIS-based (indirect) method, in the Dashte Barm site (Quickbird image), using the $10,000 \mathrm{~m}^{2}$ plot area, and in the llam site (WorldView-2 image), using the $1,000 \mathrm{~m}^{2}$ plots provided better results for classification (Fig. 8).

\section{Discussion}

In this study, the forest canopy cover density of two forest sites was mapped using direct image classification and indirect classification (integration of RS and GIS) methods. It is the traditional way to use a direct-method in classifying forest areas using satellite images through plot-based classification with a moderate accuracy result. However, to improve the classification results, we tried to use an indirect method, which is an integration of tree-based remote sensing (RS) classification, and then using the geographical information system (GIS) capability tools for extracting the tree crowns and then computing the plot-based canopy cover density classes. We also tried to find the most appropriate plot area for forest canopy cover mapping in both direct and indirect methods with different areas.

According to the obtained results, it was found that in the direct method, the forest canopy cover map does not have high accuracy and the best result was $57.39 \%$ for the Dashte Barm site (Quickbird) and 46.27\% for the llam site (WorldView-2). As can be seen in Table 4, the classification results for both sites are not of acceptable accuracy. The main reason is the mixing of the spectral responses of vegetation and soil as well as the variety of the tree covers densities in Zagros regions. Since, our the study areas are sparse and semi-dense forest and; so in a plot-based classification, due to the spectral interference of vegetations dominantly trees with soil, separating different canopy cover density classes from each other will be with wrongs so that it is not possible to classify images with desired classifications with high 
accuracy (Naseri et al. 2019). Although, in this study, the SAVI vegetation index was used to reduce the effect of soil and increases the reflectivity of plants with a low percentage of cover (Imani et al. 2018), as plot-based training samples, the impact of soil its effects have remained yet. These results were expectable and consistent with previous studies such as results of Abdollahi et al. (2010), Parma and Shataee. (2010) in the other regions Zagros forest using 6 meters resolution of IRS_LISS-IV images or by Naseri et al. (2004), Parma and Shataee. (2010) and Shahvali et al. (2012) using ETM + data. In the arid and semi-arid forest zones where have sparse and semi-dense forest cover, the literature reviews of last previous studies showed that in the plot-based classification of forest canopy cover density mapping, using high-resolution images compare to medium resolutions cannot be more effective to considerable improvement. Of course, it is necessary to pay attention to the fact that in areas similar to the studied forests, more images with low resolution and relatively high have been used to prepare the canopy cover of trees, the results of which also show there has been insufficient accuracy of these images (Boyaci et al., 2017). However, in a study conducted in forests with high vegetation cover, Banerjee et al. (2014) and Rahimizadeh et al. (2020) presented the canopy cover classification of trees with high accuracy using a direct-method using the Landsat-TM and Spot-7 satellite images, respectively.

It should be also considered that in Iran with about 14 million hectares of forest, the dense forests covering only $12.4 \%$ of the total forest area, and the rest of the forest areas have semi-dense and open canopy cover (FRWMO, 2020). Therefore, paying attention to these forests and obtaining accurate information about the canopy cover rate and its percent is of great importance for their current and future management. Therefore, using techniques and methods such as the combination of remote sensing (RS) and geographical Information Systems (GIS) are necessary to improve the results. The idea of separating the accurate boundary of tree crowns on very high-resolution satellite images as pan-sharpened with a resolution of lower than 0.5 meters or aerial digital photos taken by airplanes or UAV drones and then considering the crown areas in a plot to computing canopy cover densities is a way to overcome the problems of previous methods.

The results of the RS-GIS based method for classifying the forest canopy cover density have shown a considerable improvement compared to the direct-method in both sites. As can be seen in Table 6, the results of this method have higher overall accuracies than the highest classification results using the direct-method. Overall, the RS-GIS-based method could improve the classification results by an average of $23.25 \%$ for the Quickbird image and $17.69 \%$ for the WorldView-2 image so that overall accuracy of about 83 percent and Kappa coefficient of 0.74 were obtained in the llam site. According to the results of Chuang et al. (2011), if the overall accuracy is more than $70 \%$, the accuracy of production drawings is reliable. Therefore, the use of the RS-GIS method provided satisfactory results for canopy cover mapping.

The use of remote sensing technology is important due to lower financial costs and more time savings (Saraskanrood et al., 2019). Therefore, the issue that was considered in this study was the appropriate time to prepare the intended maps. Of course, the more accurate the information used in a shorter period, the more valuable that method is. In the methods studied in this study, it was found that the direct classification method, according to the area of training samples and the number of effective pixels in the 
classification, processing time can be variable and the larger the area of training samples, so the canopy classification time of trees increases. Therefore, in using images with high spatial resolution on a larger scale, powerful and high-performance systems are needed. However, this problem was solved in the RSGIS based classification method, and after the initial classification, which was done to separate the crown area of the trees, the rest of the steps were done easily, faster, and with less time (less than 1 hour). It should be noted that the mastery and experience of the researcher can be effective during processing.

Also in this study, the most appropriate plot area was presented to achieve the highest classification accuracy. In forest inventories, selecting the optimal sample area must be done for sufficiently and accurate gathering information with considering accuracy and time-cost factors (Mirzaei et al. 2014). As the results showed, in both used methods, with changing the plot area, the classification results also will change depending on forest canopy condition.

As can be seen in Fig. 8, in the direct-method, the graphs show a specific trend from 1000 to $10000 \mathrm{~m}^{2}$ plot areas so that with increasing the plot area, the accuracies increased so that classifications with the $5000 \mathrm{~m} 2$ and 10,000 $\mathrm{m} 2$ plot areas have high performance. In conclusion for direct classifications, the area of larger plots has been able to improve the classification results, however, according to the FAO (2000) definition, which is considered the areas of more than 0.5 as one of the factors for the definition of forest area, so use it makes more sense than plots larger than $5,000 \mathrm{~m}^{2}$.

In the indirect (RS-GIS based) method, first, the trend of the diagram is downward and then is upward so that with increasing of plot area from $1000 \mathrm{~m}^{2}$ to $2500 \mathrm{~m}^{2}$, the accuracies will decrease but from $2500 \mathrm{~m}^{2}$ to $10000 \mathrm{~m}^{2}$, the result accuracies are increased. However, in the llam site and WorldView-2 images, plots with $1000 \mathrm{~m}^{2}$ have the best results. These differences of accuracies in the two sites refer to different variety of forest canopy cover density in the sites. It seems that in forests with a variety of forest canopy cover classes, due to be more number of classes as well as to be near to spectral responses of canopy cover density classes, separation of classes is very difficult.

\section{Conclusion}

In general, the results show that the combination of remote sensing techniques and GIS tools can improve the results of forest canopy cover classification in both study areas. Therefore, separating the boundaries of tree crowns and computing these areas for canopy cover densities using GIS tools is a new method in future research in the arid and semi-arid zones with sparse forests. In this regard, the use of high-resolution images can have a positive effect on improving the results. Also, the results showed that concerning the conditions of canopy cover density of forest stands and in the forest regions with thin and semi-thin forest canopy cover densities such as Dahte Barm site, the use of plots with areas of $10000 \mathrm{~m}^{2}$ and more are suitable for direct classification. But, for RS-GIS based classifications, the plot areas of $1000 \mathrm{~m}^{2}$ are optimal due to time and cost saving. However, in the forest regions with semi-dense to severity dense canopy cover classes such as the llam site, using $1000 \mathrm{~m} 2$ plot areas is enough and optimal. The results also showed that the forest canopy cover density map of Dashte Barm site using 
Quickbird images had more accuracy compared to the map of the llam site using WorldView-2 images due to the high variation of canopy cover densities in the llam site.

\section{Declarations}

Ethics approval and consent to participate:

'Not applicable'

Consent for publication:

'Not applicable'

Availability of data and material:

'Not applicable'

Competing interests:

The authors declare that they have no competing interests

\section{Funding}

'Not applicable'

\section{Authors' contributions}

'All authors read and approved the final manuscript'

\section{Acknowledgements:}

'Not applicable'

\section{References}

1. Abdollahi H, Shataee Jouibari S h, Sepehri A, Zanganeh H (2010) Comparing Investigation on Landsat-ETM+ and IRS-P6-LISS IV Data for Canopy Cover Mapping of Zagros Forests (Case study, Javanroud forests). J Wood For Sci Technol 17:1-18

2. Abdollahnejad $A$, Panagiotidis $D$, Surový $P$ (2017) Forest canopy density assessment using different approaches - Review. J For Sci 63:107-116. https://doi.org/10.17221/110/2016-JFS

3. Adeli K, Fallah A, Kooch Y (2008) An appropriate plot area for analyzing canopy cover and tree species richness in Zagros forests. Pakistan J Biol Sci 11:103-107.

https://doi.org/10.3923/pjbs.2008.103.107 
4. Afshar S (2012) Estimation of Zagros forest canopy characteristics using a combination of satellite images and auxiliary data (Case study: Forests around llam city). Gorgan University of Agricultural Sciences and Natural Resources, Faculty of Agriculture and Natural Resources

5. Asrat Z, Taddese H, Ørka HO, et al (2018) Estimation of forest area and canopy cover based on visual interpretation of satellite images in Ethiopia. Land 7:92

6. Banerjee K, Panda S, Bandyopadhyay J, Jain MK (2014) Forest canopy density mapping using advance geospatial technique. Int J Innov Sci Eng Technol 1:358-363

7. Bauer T, Steinnocher K (2001) Per-parcel land use classification in urban areas applying a rule-based technique. GeoBIT/GIS 6:24-27

8. Behbahani N, SeyedRhashid F, Farzadmehr J, et al (2009) Use of vegetation indices of ASTER-L1B images in estimating the canopy area of single trees in wooded rangelands, case study; Tag Ahmad Shahi - South Khorasan. Range 4:93-103

9. Birth GS, McVey GR (1968) Measuring the color of growing turf with a reflectance spectrophotometer 1. Agron J 60:640-643

10. Bonnell J (2011) Implementation of a New Sigmoid Function in Backpropagation Neural Networks

11. Boyaci D, Erdogan M, Yildiz F (2017) Pixel-versus object-based classification of forest and agricultural areas from multiresolution satellite images. Turkish J Electr Eng Comput Sci 25:365375. https://doi.org/10.3906/elk-1504-261

12. Chuang C-W, Lin C-Y, Chien C-H, Chou W-C (2011) Application of Markov-chain model for vegetation restoration assessment at landslide areas caused by a catastrophic earthquake in Central Taiwan. Ecol Modell 222:835-845

13. Erfanifard Y, Khodaei Z, Shamsi RF (2014) A robust approach to generate canopy cover maps using UltraCam-D derived orthoimagery classified by support vector machines in Zagros woodlands, West Iran. Eur J Remote Sens 47:773-792

14. Eskandari S, Reza Jaafari M, Oliva P, et al (2020) Mapping Land Cover and Tree Canopy Cover in Zagros Forests of Iran: Application of Sentinel-2, Google Earth, and Field Data. Remote Sens 12:1912

15. FAO. 2000. The State of Food Insecurity in the World 2000, Rome.

16. Forests, Rangelands, and Watershed Management Organization of Iran (FRWMO), 2020. https://frw.ir/02/fa/staticpages/page.aspx?tid=1500

17. Gitelson AA 8c Merzlyak, MN (1997) Remote estimation of chlorophyll content in higher plant leaves. Int J Remote Sens 18:2692-2697

18. Hoosem Artificial Intelligence Academy, 2018. https://howsam.org/activation-functions-neuralnetworks

19. Imani J, Ebrahimi A, Gholinejad B, Tahmasebi P (2018) Comparison of NDVI and SAVI in three plant communities with different sampling intensity (case study: Choghakhour Lake rangelands in Charmahal \& Bakhtiri). Iran J Range Desert Res 25: 
20. Ismail MH (2010) Determining and Mapping of Vegetation using GIS and Phytosociological Approach in Mount Tahan, Malaysia. J Agric Sci 2:80-89. https://doi.org/10.5539/jas.v2n2p80

21. Karami O, Fallah A, Shataei S, Latifi H (2017) Investigation on the feasibility of mapping of oak forest dieback severity using Worldview-2 satellite data (Case study: llam forests). Iran J For Poplar Res 25:452-462

22. Kim SR, Lee WK, Kwak DA, et al (2011) Forest cover classification by optimal segmentation of high resolution satellite imagery. Sensors 11:1943-1958. https://doi.org/10.3390/s110201943

23. Mahdavi A, Aziz J (2020) Estimation of Semiarid Forest Canopy Cover Using Optimal Field Sampling and Satellite Data with Machine Learning Algorithms. J Indian Soc Remote Sens 1-9

24. Mirzaei M, Bonyad AE, Pourbabaei H (2014) Investigation Comparison of Transect Sampling Methods in Estimation of Quantitative Characteristics of Forest (Case study: Daalaab forests of llam). J For Wood Prod 1:61-72

25. Naghavi H, Fallah A, Shataee S, et al (2014) Canopy cover estimation across semi-Mediterranean woodlands: application of high-resolution earth observation data. J Appl Remote Sens 8:83524

26. Naseri F, DarvishSeffat A, Sobhani H, Namiranian M (2004) Evaluation of Landsat 7 data to prepare a forest density map in arid areas and Semi-dry. Nat Resour Iran 57:109-119

27. Naseri MH, Shataee Jouibari S, Mohammadi J, Ahmadi S (2019) Capability of Rapid Eye Satellite Imagery to Map the Distribution of Canopy Trees in Dashtebarm Forest Area of Fars Province. Ecol Iran For 7:58-69

28. Nourian N, Joibary SS, Mohammadi J (2016) Assessment of different remote sensing data for forest structural attributes estimation in the Hyrcanian forests. For Syst 25:9

29. Ogwankwa F (2020) Using GIS to Assess Sustainable Land Management; A case of Manyatta B , an Informal Settlement in Kisumu, Kenya. https://doi.org/10.13140/RG.2.2.35438.84803

30. Parma R, Shataee S (2010) Capability study on mapping the diversity and canopy cover density in Zagros forests using ETM+ images (case study Ghalajeh forests, Kirmanshah province). Iran J For 2:231-242

31. Quynh Trang NT, Toan LQ, Huyen Ai TT, et al (2016) Object-Based vs. Pixel-Based Classification of Mangrove Forest Mapping in Vien An Dong Commune, Ngoc Hien District, Ca Mau Province Using VNREDSat-1 Images. Adv Remote Sens 05:284-295. https://doi.org/10.4236/ars.2016.54022

32. Rahimizadeh N, Babaie Kafaky S, Sahebi MR, Mataji A (2020) Forest structure parameter extraction using SPOT-7 satellite data by object- and pixel-based classification methods. Environ Monit Assess 192:. https://doi.org/10.1007/s10661-019-8015-x

33. Rouse Jr JW, Haas RH, Schell JA, Deering DW (1974) Monitoring vegetation systems in the Great Plains with ERTS. Third Earth Resources Technology Satellite-1 Symposium: Volume 1; Technical presentations, section B, SC Freden, EP Mercanti, and MA Becker, Eds., NASA Special Publ. NASA-SP351-VOL-1-SECT-B, A 20, 309-317

34. Saraskanrood SA, Khodabandelo B, Naseri A, Moradi A (2019) Extracting Land Use Map based on a comparison between Pixel-Based and Object-Oriented Classification Methods Case Study: Zanjan 
City. Sci Q Geogr Data 28:195-208

35. Shahvali KA, M P, Fatehi P (2012) Forest cover density mapping in sparse and semi dense forests using forest canopy density model (Case study: Marivan forests)

36. TaheriSarteshnizi M (2013) Study of different methods of estimating canopy cover in Iranian oak forests in the South Zagros. Yasuj University, Faculty of Agriculture and Natural Resources

37. Wang L, Sousa WP, Gong P (2004) Integration of object-based and pixel-based classification for mapping mangroves with IKONOS imagery. Int J Remote Sens 25:5655-5668. https://doi.org/10.1080/014311602331291215

38. Williams MS, Patterson PL, Todd Mowrer H (2003) Comparison of ground sampling methods for estimating canopy cover. For Sci 49:235-246

39. Xu X, Cao D, Zhou Y, Gao J (2020) Application of neural network algorithm in fault diagnosis of mechanical intelligence. Mech Syst Signal Process 141:106625. https://doi.org/10.1016/j.ymssp.2020.106625

\section{Figures}

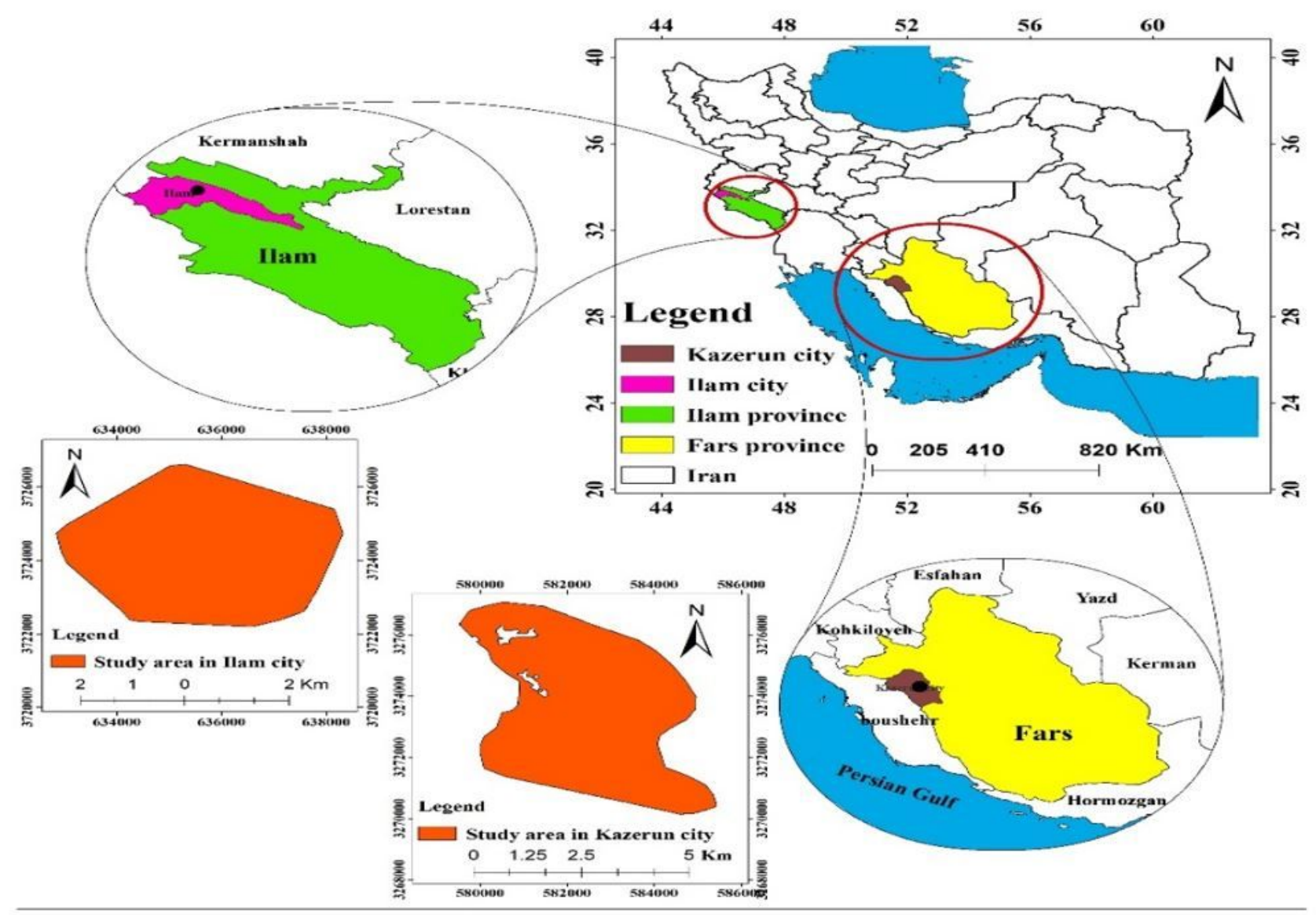

Figure 1

Location of the studied sites 

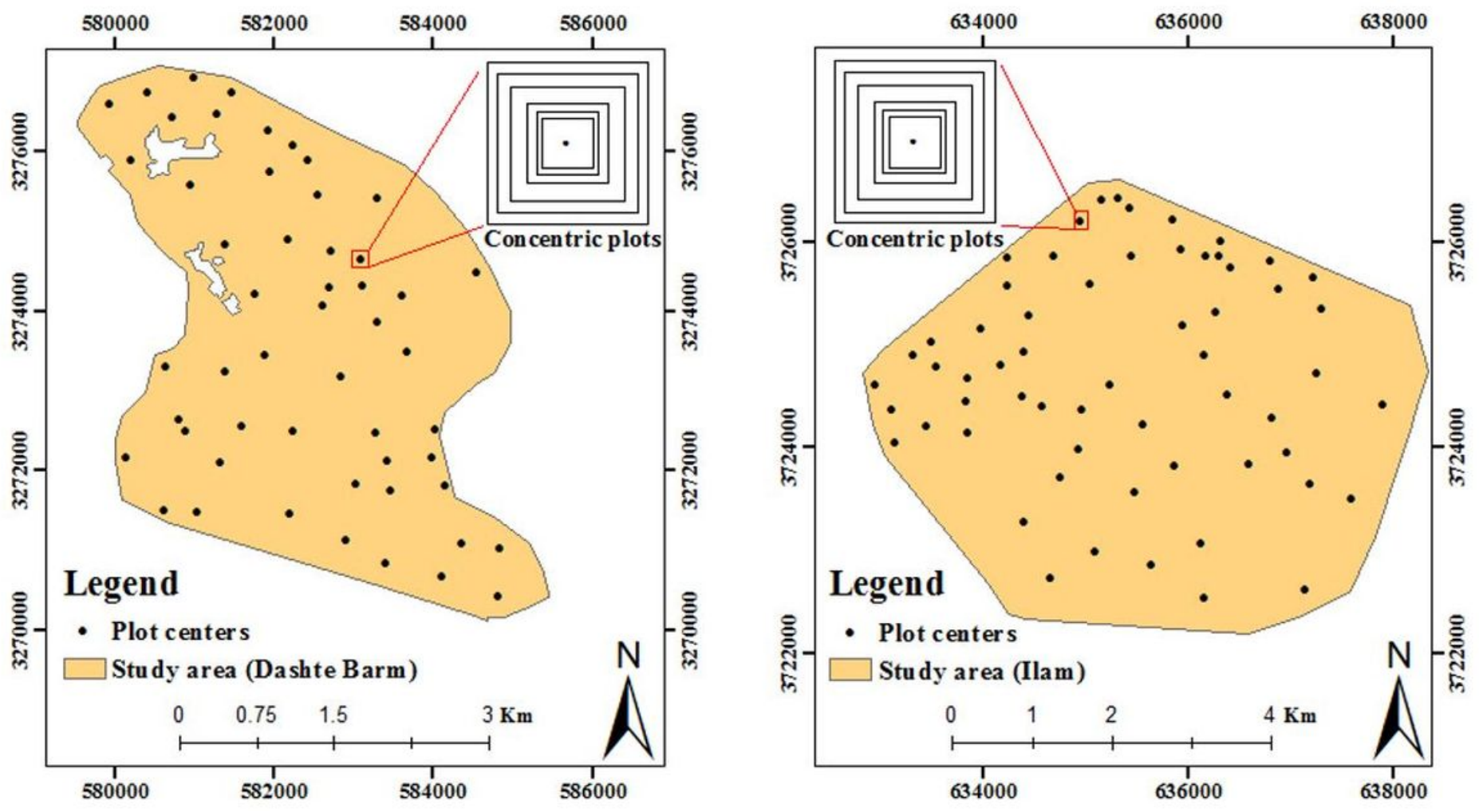

Figure 2

Spatial distribution of plots
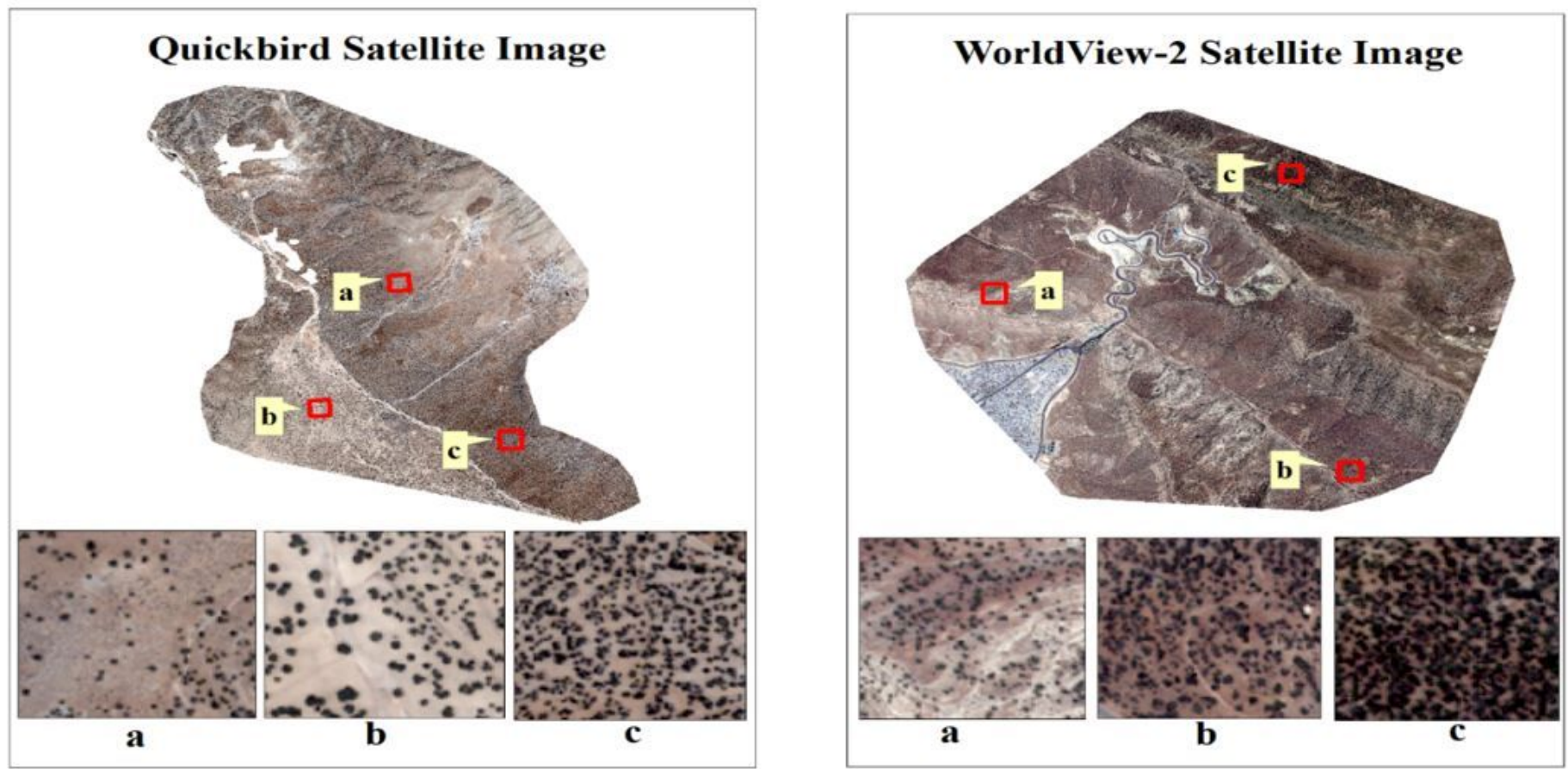

Figure 3 
Color composite images (RGB) of both sites with three slices of the different canopy cover densities

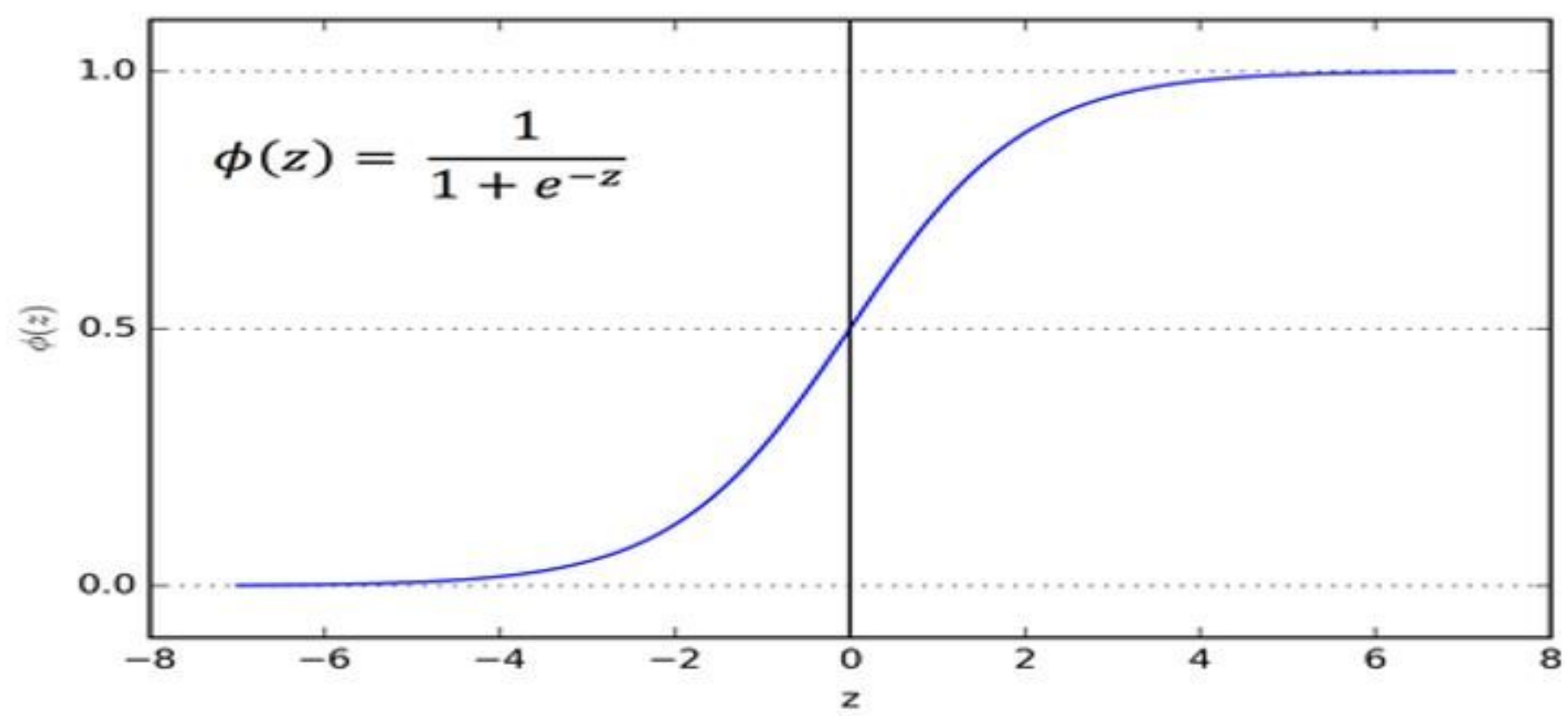

Figure 4

Logistic Activation Function (Hoosem Artificial Intelligence Academy, 2018)
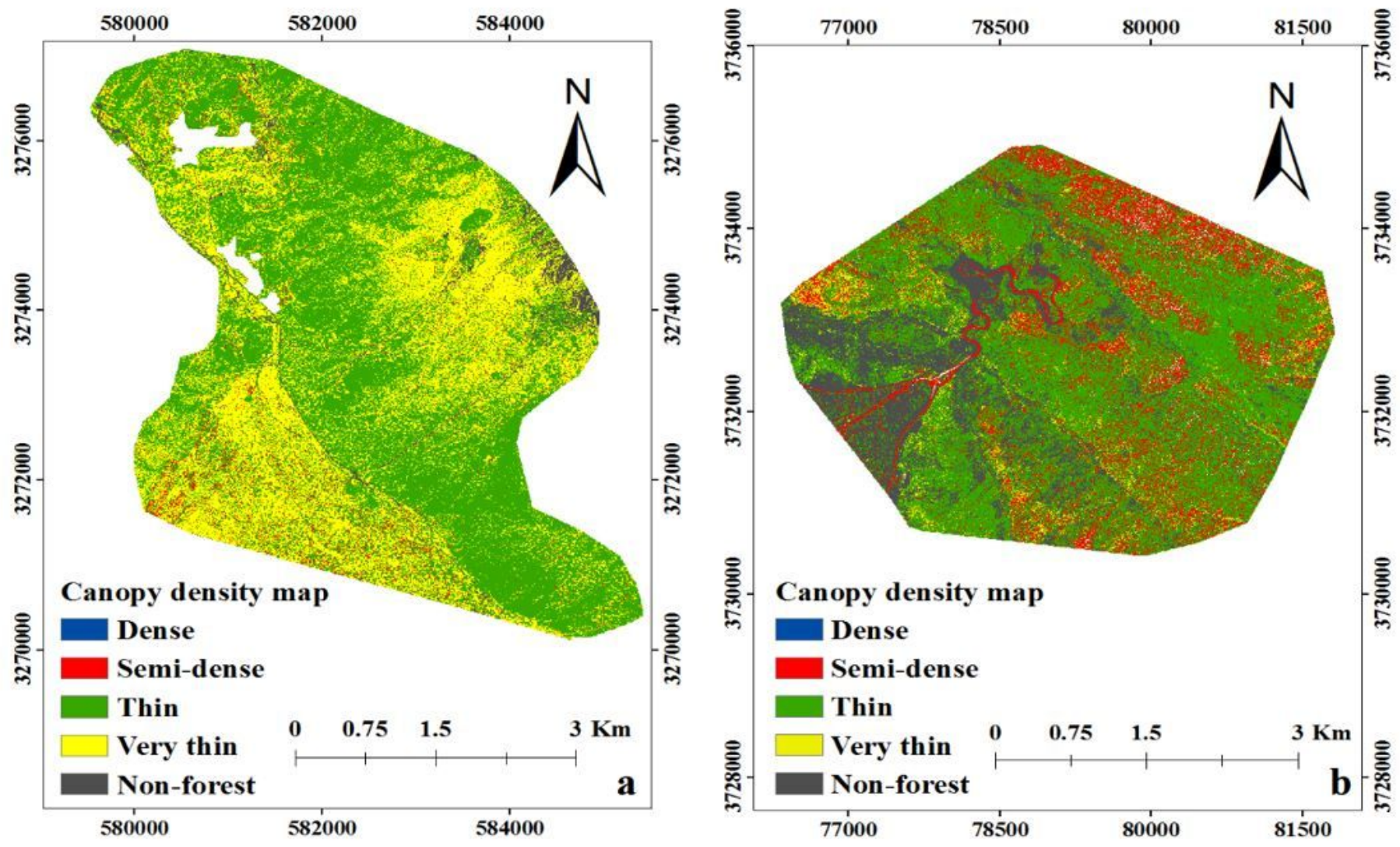


\section{Figure 5}

Forest canopy cover density maps by $7500 \mathrm{~m} 2$ plot areas at the Dashte Barm site (a), and $5000 \mathrm{~m} 2$ plot areas at the llam site (b).

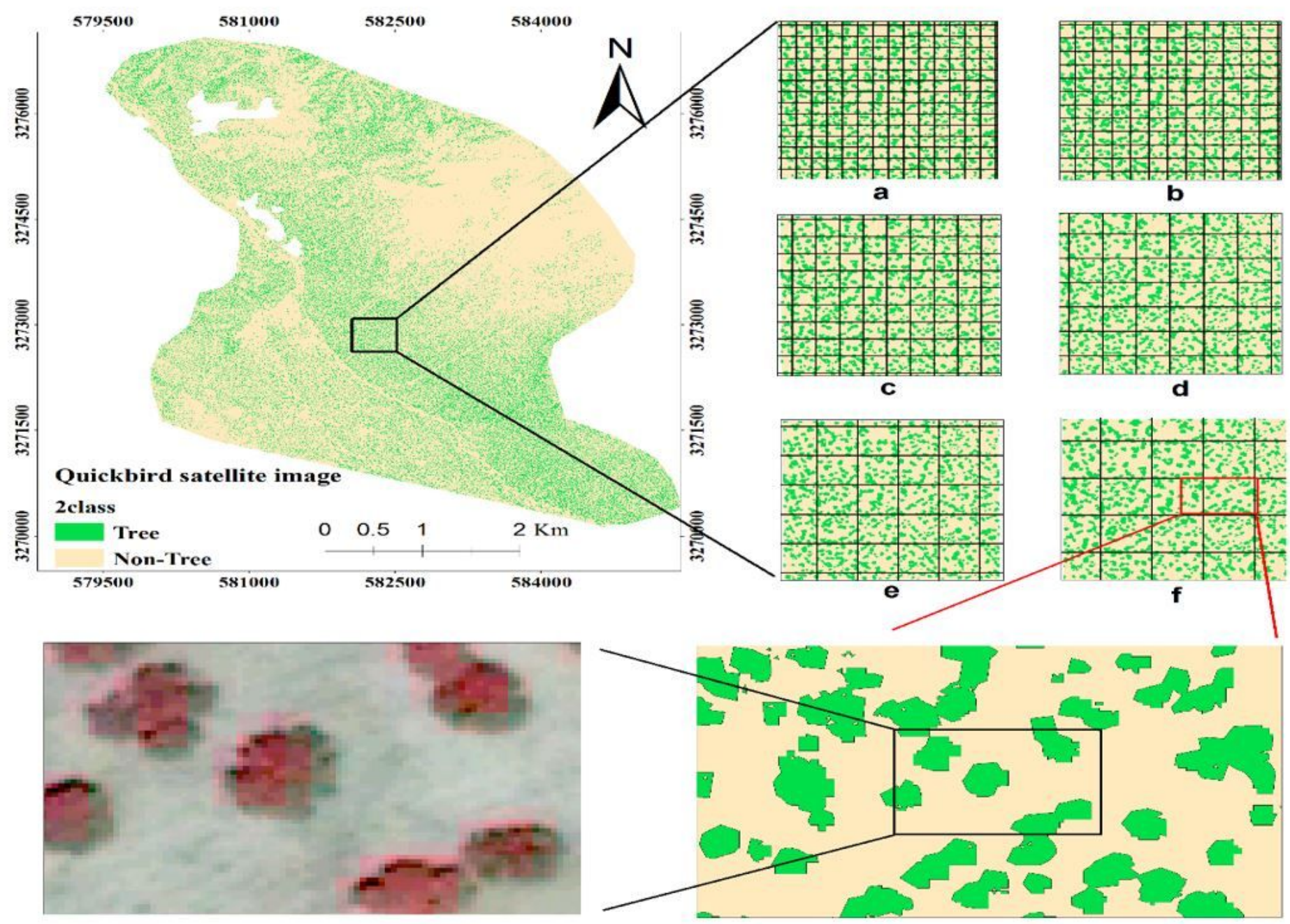

Figure 6

Classified map (tree and non-tree) of Quickbird satellite image (a), $1000 \mathrm{~m} 2$ (b), $1500 \mathrm{~m} 2$ (c), $2500 \mathrm{~m} 2$ (d), $5000 \mathrm{~m} 2$ (e), $7500 \mathrm{~m} 2$ (f), and 10,000 m2 grids (g). 

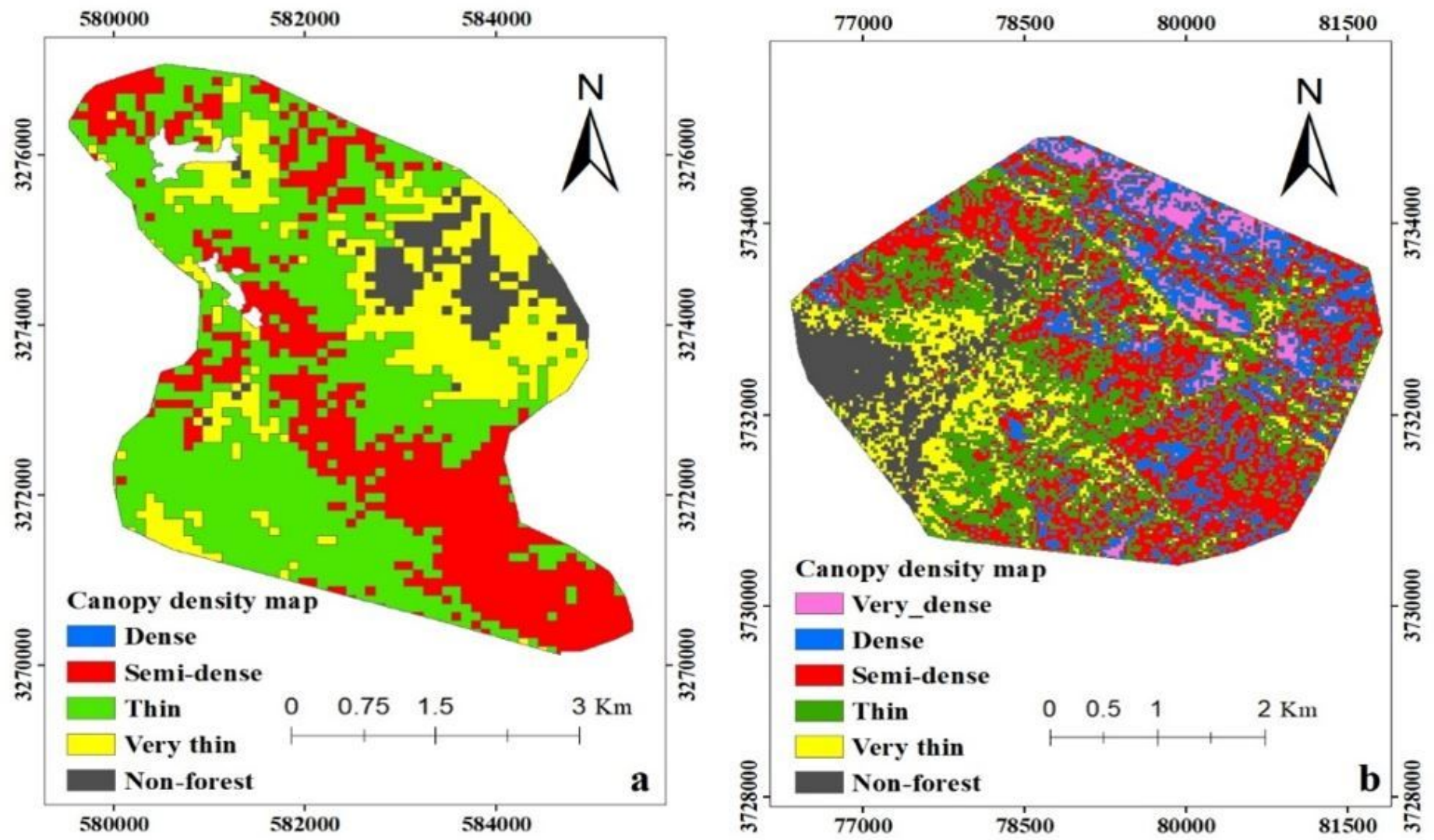

Figure 7

Tree canopy cover map, (a) using a 10,000 m2 grid in the Dashte Barm site (Quickbird image), (b) Tree canopy cover map using a $1000 \mathrm{~m} 2$ grid in the llam site (WorldView-2 image). 

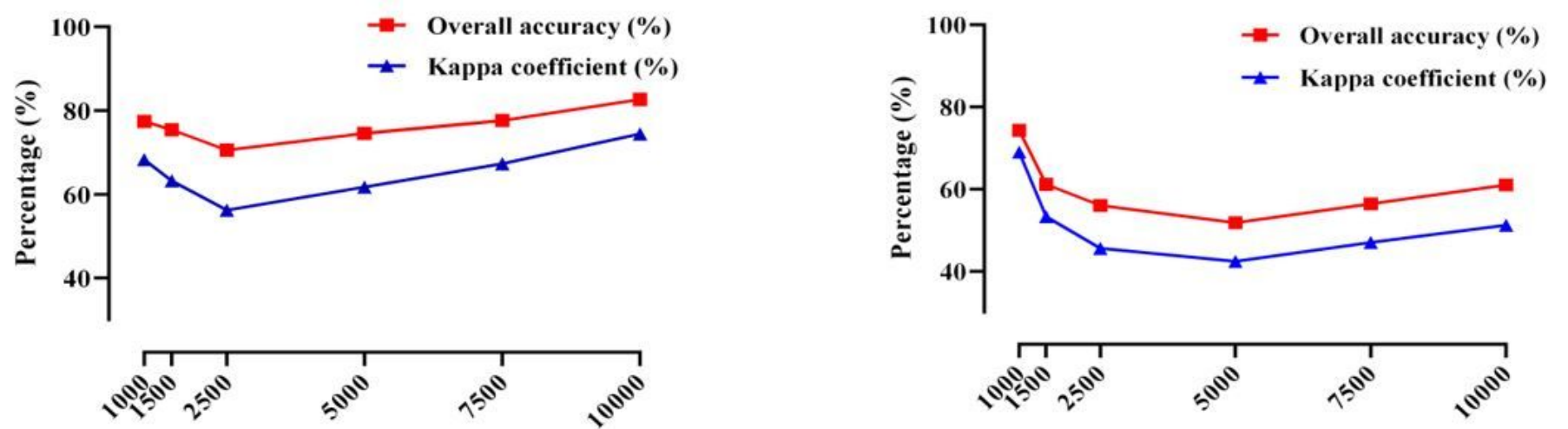

$\operatorname{Plot}\left(\mathrm{m}^{2}\right)$

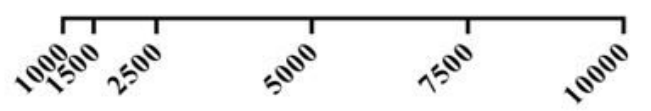

Plot $\left(\mathrm{m}^{2}\right)$

a- Quickbird Image (Indirect-method)

b- WorldView-2 Image (Indirect-method)

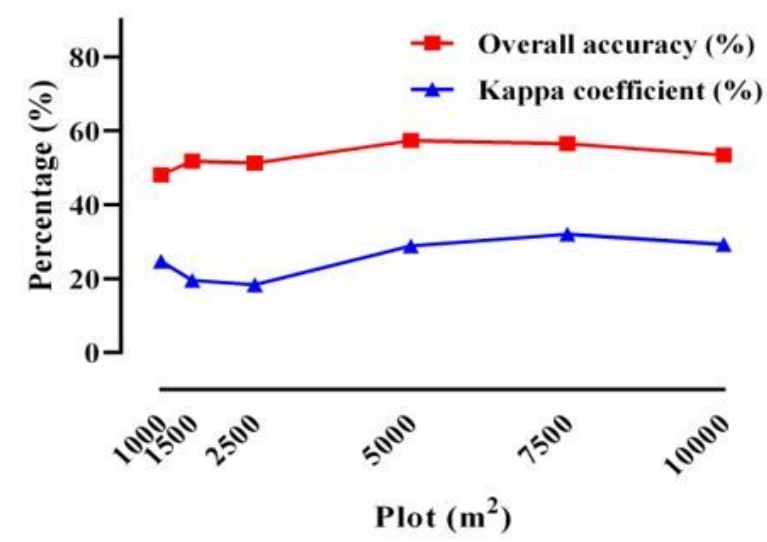

c- Quickbird Image (Direct-method)

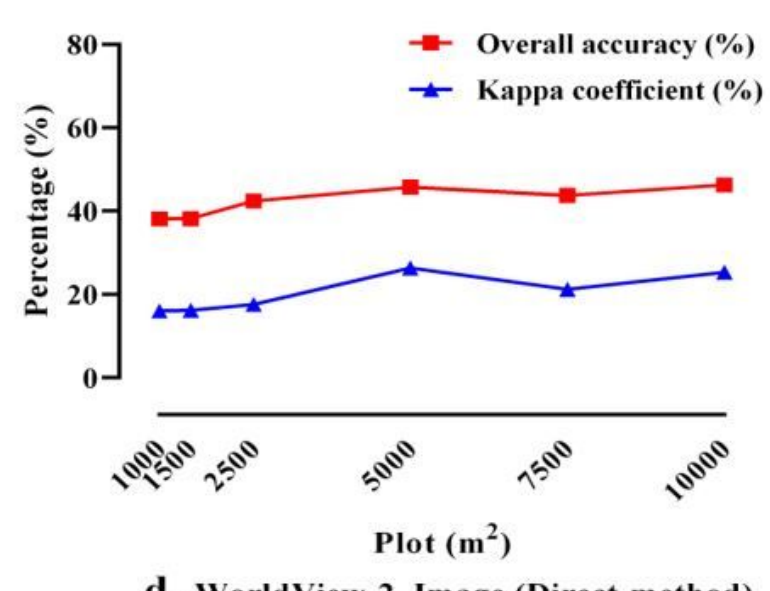

d- WorldView-2 Image (Direct-method)

\section{Figure 8}

Diagrams of the effect of plot area on the forest canopy cover classification results: a) Quickbird classified image by RS-GIS based method, b) WorldView-2 classified image by RS-GIS based method, c) Quickbird classified image by direct-method and d) WorldView-2 classified image by direct-method. 